\title{
Multidisciplinary Teams on the Battlefield: An Innovative Approach to Overcrowded Field Hospitals and Trauma Centers
}

\author{
Mohammad Javad Behzadnia ${ }^{1 *}$ \\ ${ }^{1}$ Trauma Research Center, Baqiyatallah University of Medical Sciences, Tehran, Iran \\ *Corresponding Author: Mohammad Javad Behzadnia, M.D., Assistant Professor, Trauma Research Center, \\ Baqiyatallah University of Medical Sciences, Nosrati Alley, Sheikh Bahaie St., Molla Sadra St., Vanaq Sq., Tehran, \\ Iran. Tel: +98-2181262121, Email: Behzadnia@bmsu.ac.ir
}

Received April 21, 2018; Accepted April 22, 2018; Online Published May 1, 2018

\section{Dear Editor,}

Many years ago, clinicians worked in various fields of medicine, and they made the vast majority of medical judgments and procedures. Today, the increasing population and growth in medical sciences has resulted in the development of many new medical subspecialties. Commonly, medical treatment begins with a general practitioner and progresses to a specialist in cases of complexity. Atypically, a clinician may confront an emergency situation that requires prompt action in order to save the victims. A crowd disaster at a mass gathering could easily change the normal condition of a hospital into one of crisis. This may be more apparent when it occurs on a battlefield with few medical personnel. In other words, if triage is not properly managed in an acute care setting, the other steps of the survival chain would soon be disrupted. Having organized behavior in medical teams could save time and increase efficacy. ${ }^{1}$

In such a situation, multidisciplinary groups consisting at minimum of an emergency medicine specialist, trauma surgeon, and anesthesiologist could help overcome the problem. Recently, multidisciplinary care teams have been introduced in some medical management teams. ${ }^{2,3}$ This innovation has also been experienced in other fields, such as situations of neurological problems, geriatric issues, and cancerous tumor management.,

Multidisciplinary teams could determine the priority of each situation and manage it as well.
It is strongly recommended that multidisciplinary teams be created and trained in trauma and field hospital management to overcome the problem of insufficient medical staff facing battlefield crowding.

\section{Conflict of Interest Disclosures}

The author declares that he has no conflicts of interest.

\section{Ethical Approval}

Not applicable.

\section{References}

1. van der Haar S, Koeslag-Kreunen M, Euwe E, Segers M. Team leader structuring for team effectiveness and team learning in command-and-control teams. Small Group Res. 2017;48(2):215-248. doi:10.1177/1046496417689897.

2. Powell RE, Lovett PB, Crawford A, et al. A multidisciplinary approach to impact acute care utilization in sickle cell disease. Am J Med Qual. 2018;33(2):127-131. doi:10.1177/1062860617707262.

3. Prabhakaran S, Lee J, O'Neill K. Regional learning collaboratives produce rapid and sustainable improvements in stroke thrombolysis times. Circ Cardiovasc Qual Outcomes. 2016;9(5):585-592. doi:10.1161/CIRCOUTCOMES.116.003222.

4. Mangram AJ, Shifflette VK, Mitchell CD, et al. The creation of a geriatric trauma unit "G-60". Am Surg. 2011;77(9):1144-1146.

5. Strong $\mathrm{S}$, Blencowe NS, Fox $\mathrm{T}$, et al. The role of multidisciplinary teams in decision-making for patients with recurrent malignant disease. Palliat Med. 2012;26(7):954-958. doi:10.1177/0269216312445296. 